\title{
Factors Associated with Mortality of Walleyes and Saugers Caught in Live-Release Tournaments
}

\author{
Harold L. Schramm JR.* \\ U.S. Geological Survey, Mississippi Cooperative Fish and Wildlife Research Unit, \\ Mail Stop 9691, Mississippi State, Mississippi 39759, USA
}

\author{
BRUCE VONDRACEK \\ U.S. Geological Survey, Minnesota Cooperative Fish and Wildlife Research Unit, University of Minnesota, \\ 1980 Folwell Avenue, St. Paul, Minnesota 55108, USA

\section{William E. FRENCH ${ }^{1}$} \\ Department of Wildlife, Fisheries, and Conservation, University of Minnesota, \\ 1980 Folwell Avenue, St. Paul, Minnesota 55108, USA \\ PATRICK D. GeRARD \\ Department of Applied Economics and Statistics, Clemson University, Clemson, South Carolina 29634, USA
}

\begin{abstract}
We measured the initial mortality (fish judged nonreleasable at weigh-in), prerelease mortality (fish judged nonreleasable 1-2 h after weigh-in [which includes initial mortality]), and postrelease mortality (fish that died during a 5-d retention in net-pens) in 14 live-release tournaments for walleye Sander vitreus conducted in April-October 2006 and April-July 2007 in lakes and rivers in Michigan, Minnesota, North Dakota, South Dakota, and Wisconsin. Among the 14 events, initial mortality was 0-28\%, prerelease mortality was $3-54 \%$, and postrelease mortality was $0-100 \%$; the mortality of reference fish (walleyes $\geq 31$ $\mathrm{cm}$ long that were captured by electrofishing and held in net-pens with tournament-caught walleyes to measure postrelease mortality) was $0-97 \%$. Mortality was generally low in events conducted when water temperatures were below $14^{\circ} \mathrm{C}$ but substantially higher in events when water temperatures were above $18^{\circ} \mathrm{C}$. The mortality of reference fish suggests that capture by electrofishing and minimal handling when the water temperature exceeds $19^{\circ} \mathrm{C}$ results in high mortality of walleyes that is largely the result of the thermal conditions immediately after capture. Mortality was not related to the size of the tournaments (number of boats), the total number or weight of walleyes weighed in, or the mean number or weight of walleyes weighed in per boat. Mortality was positively related to the depth at which walleyes were caught and the live-well temperature and negatively related to the live-well dissolved oxygen concentration. Surface water temperature was the best predictor of mortality, and models were developed to predict the probability of prerelease and postrelease mortality of 10,20 , and $30 \%$ or less of tournament-caught walleyes due to water temperature.
\end{abstract}

Organized fishing tournaments began in North America in the 1960s and rapidly grew in number (Schramm et al. 1991; Schramm and Hunt 2007). The initial surge in tournaments was directed primarily at black bass Micropterus spp. Substantial growth in the size and number of black bass tournaments elicited concern among fishery managers and tournament organizations about high exploitation and depletion of fish. Live release was championed by several tournament organizations to reduce potential depletion of black bass populations and soon became standard

\footnotetext{
* Corresponding author: hschramm@cfr.msstate.edu

${ }^{1}$ Present address: Department of Wildlife and Fisheries, South Dakota State University, Brookings, South Dakota 57007, USA.
}

Received January 13, 2009; accepted October 8, 2009 Published online January 14, 2010 procedure for bass tournaments. Concern about the effectiveness of live release (Schramm et al. 1991) stimulated numerous studies of mortality of tournament-caught black bass (reviewed in Wilde 1998; Edwards et al. 2004; Schramm et al. 2006) and development of several procedural guides to help anglers and tournament organizers achieve high survival of released bass (e.g., Gilliland and Schramm 2002; Tufts and Morlock 2004).

Organized tournaments in which anglers fish for walleye Sander vitreus and sauger $S$. canadensis began in the late 1970s (Schramm et al. 1991). Trends in walleye tournaments have not been measured but, paralleling the expansion of inland fishing tournaments (Schramm and Hunt 2007), appear to have rapidly grown in number and participation. Most walleye tournaments were live-release events, and walleye 
anglers, tournament organizers, and fishery managers were, and remain, concerned about the effectiveness of live-release procedures. Mortality rates measured in live-release walleye tournaments have ranged from zero to greater than $50 \%$ for both initial mortality (fish dead at the weigh-in) and postrelease mortality (mortality measured for up to 1 week after the tournament; Goeman 1991; Fielder and Johnson 1994; Hoffman et al. 1996; Graeb et al. 2005). Rough-water fishing conditions and tournament procedures were suggested to affect survival of tournamentcaught walleyes (Goeman 1991). Both initial mortality (Hoffman et al. 1996) and postrelease mortality (Graeb et al. 2005) of walleyes were positively related to water temperature, as has been found for black bass (Wilde 1998), but the temperature at which mortality begins to rapidly increase has not been clearly defined.

Measurement of mortality of walleyes caught in modern, live-release tournaments is important to various fisheries stakeholders. Fisheries managers seek information on mortality of tournament-caught walleyes to assess the effects of tournaments on walleye populations and to guide management decisions about walleye tournaments. For example, Minnesota and South Dakota do not allow live-release walleye tournaments during summer months when mortality is presumed to be high because of high water temperatures. Tournament organizations need information about mortality of tournament-caught walleyes to assess the effectiveness of tournament operation and fish handling procedures and to provide guidance for improving walleye survival. Some recreational (nontournament) walleye anglers have expressed concern about the harvest of walleyes in tournaments and use of the resource. Although biological data may not resolve social conflicts, tournament anglers should be made aware of the fate of the fish they catch, and recreational anglers should be informed about the relative harvests by tournament and recreational anglers. Hence, measures of mortality and its relationships with environmental conditions provide a scientific basis for addressing angler concerns, effectively managing walleye tournaments, and integrating tournaments with recreational walleye fisheries.

Several studies have provided measures of mortality of tournament-caught walleyes (e.g., Goeman 1991; Fielder and Johnson 1994; Hoffman et al. 1996; Graeb et al. 2005). Except for the recent study by Graeb et al. (2005) that assessed three similar tournaments conducted at water temperatures ranging from $7-19^{\circ} \mathrm{C}$, the varied assessment methods or the lack of assessment across a range of environmental conditions with consistent methods limit the use of previous results for predicting mortality in live-release walleye tourna- ments. Further, tournament and fish handling procedures have changed throughout the evolution of walleye tournaments, thereby challenging the contemporary validity of earlier estimates of walleye mortality in live-release tournaments. To provide information needed by fishery managers, organizers and participants in walleye tournaments, and the general public, this research (1) estimated mortality of walleyes and saugers caught in 14 live-release walleye tournaments that employed a consistent format throughout two tournament seasons, (2) assessed potential relationships between mortality and environmental and tournament conditions, and (3) identified environmental and tournament-related variables that could be used to predict the likelihood of walleye mortality in tournaments.

\section{Methods}

This study was conducted during the open-water walleye tournament seasons in 2006 and 2007. Data were obtained for seven tournaments conducted throughout the April-October 2006 walleye tournament season to assess the effects of a spectrum of environmental conditions on tournament-caught walleye survival. Tournaments evaluated in the second year of the study were selected to better evaluate those environmental conditions identified in 2006 that appeared to influence mortality (Schramm et al. 2008).

Tournament and weigh-in procedures.-All tournaments were conducted by FLW Outdoors using similar facilities and fish handling protocols. The tournaments were live-release events, and anglers were penalized by subtracting $0.23 \mathrm{~kg}$ from the weight of their total catch for each fish that was judged nonreleasable (see below) by a tournament official. As is typical of walleye tournaments, fishing was allowed with live and artificial baits. The fishing day began at 0700 hours and ended at 1500 hours. Two anglers fished from a boat, and the daily tournament limit was five walleyes and saugers in aggregate per boat in all events. All boats had aerated live wells.

All tournaments used an in-water weigh-in protocol described by Tufts and Morlock (2004) that minimizes the adverse effects of air exposure on walleyes (Killen et al. 2006). At the end of the fishing day, contestants transferred their catch from their boat's live well to a reinforced plastic bag containing 8-12 L of live-well, lake, or river water and then transported their catch to the weigh-in facility; the large bag was made specifically for carrying walleyes and was provided by FLW Outdoors. Transport time from the boat to the weigh-in facility was less than $4 \mathrm{~min}$. At the weigh-in facility, fish were poured from the transport bag into a $66-\times 40-\times 25-\mathrm{cm}$ covered plastic box perforated with 
2.5-cm diameter holes to allow water circulation. The plastic boxes containing fish were immersed in oxygenated and temperature-controlled water in an aluminum trough while anglers awaited weigh-in, a time period less than $10 \mathrm{~min}$. The trough was filled with lake or river water (ambient water), and water temperature was maintained at ambient temperature when these temperatures were below $18^{\circ} \mathrm{C}$ or cooled 2 $3^{\circ} \mathrm{C}$ by the addition of ice at warmer temperatures; dissolved oxygen was maintained at greater than $8 \mathrm{mg} /$ $\mathrm{L}$ by aeration with pressurized oxygen. Immediately prior to weigh-in and with the plastic box immersed in water, a tournament official measured the fish and judged whether each fish was "releasable" or "nonreleasable." A fish was judged releasable if it had opercular movement, was responsive when handled, and could maintain a normal (dorsal-up) position in the water.

After the fish were checked for minimum length and judged releasable or nonreleasable, the contestants carried the box containing their catch to the scale to be weighed, a time period of less than $15 \mathrm{~s}$. After all water was drained, the perforated plastic box was immersed in a tank of water on a scale for up to $3 \mathrm{~min}$ to weigh the catch. The tank on the scale was filled with aerated, ambient water at approximately the same temperature as the water in the troughs where anglers awaited weigh-in; the water in the tank was replaced with fresh, temperature-adjusted water two to four times during a weigh-in. Immediately after weigh-in, contestants transported their catch in the perforated plastic boxes without water to a nearby release boat. Time from the weigh-in to the release boat was usually less than 2 min; however, delays of up to approximately $1 \mathrm{~min}$ occasionally occurred when photographs were taken of exceptional catches.

At the release boat, fish were poured into one of three aerated, 950-L tanks filled with ambient water and maintained at ambient surface temperature. Dissolved oxygen in the tanks was maintained at greater than $8 \mathrm{mg} / \mathrm{L}$ by flushing with ambient water and aeration with pressurized oxygen. The fish were held in the release boat tanks for up to $1 \mathrm{~h}$ as fish were continually added to the tanks. Dead fish were removed immediately. The number of fish added to each tank was monitored to not exceed a density of 1 fish/24 L or, based on the mean weight of $1.30 \mathrm{~kg}$ for the 5,031 fish weighed in these 14 tournaments, $1 \mathrm{~kg} / 18.5 \mathrm{~L}$ of water $($ range $=1 \mathrm{~kg} / 11.9 \mathrm{~L}$ to $1 \mathrm{~kg} / 34.8 \mathrm{~L}$ ). The release boat then traveled to a suitable deepwater release site where the fish were released. Two to three trips to release fish were necessary in events with large catches. Fish weighed in while the release boat was offshore were held in a 760-L tank filled with ambient water and mechanically aerated. The release boat was offshore for less than $15 \mathrm{~min}$, and these fish were transferred in dip nets to the tanks on the release boat when it returned.

Catch and live-well conditions.-Dissolved oxygen and water temperature were measured in the live wells of 25-80 contestants' boats at each event after they docked their boats and prior to or immediately after transferring their catch to the reinforced plastic bag for transport to weigh-in. We randomly interviewed one angler from each of 26-81 boats at each event to obtain information about the maximum depth at which they caught the fish they weighed in.

Mortality.-We obtained three measures of mortality in each tournament. Anglers were allowed to weigh saugers and walleyes, and both species were collectively included in mortality estimates. Initial mortality was the percentage of fish judged nonreleasable by FLW personnel at weigh-in. Prerelease mortality was the percentage of fish judged nonreleasable by research personnel when fish were released from the release boat. The same criteria used to judge fish releasable or nonreleasable before weigh-in were used to judge fish released from the release boat, and the same individual (W.E.F.) judged the fish at the time of release in all events. Because all fish weighed in were put into the release-boat tanks, prerelease mortality included initial mortality. We considered prerelease mortality a realistic measure of short-term mortality (i.e., exclusive of postrelease mortality; see below) because it included the cumulative effects of capture, live-well confinement, and weigh-in on survival and provided time for fish to recover from handling. Fish were also evaluated for hyperbuoyancy at the time of release. Hyperbuoyancy was readily detected in holding tanks as fish that appeared otherwise healthy and uninjured that were floating on their side or ventrum up and unable to submerge and retain a normal dorsal-up position.

Prerelease mortality was not determined for the Isle or Bemidji events. Both events were in Minnesota, and Minnesota Department of Natural Resources (MDNR) regulations prohibited release of walleyes caught in tournaments conducted in July and August. These tournaments were conducted as typical live-release tournaments (i.e., fish were judged as releasable or nonreleasable prior to weighing, anglers were penalized for nonreleasable fish, and fish were transported to tanks on the live-release boat) but, except for randomly selected fish judged releasable and used for postrelease mortality trials, fish were euthanatized and properly disposed immediately after they were put into tanks on the live-release boat in compliance with MDNR regulations. Postrelease mortality was measured for 5 $\mathrm{d}$ after the tournament by monitoring the survival of 
tournament-caught fish judged releasable at the time of release. Ten to 15 randomly selected tournamentcaught fish were stocked into each of four net-pens in each event. The net-pens were made of 1.9-cm-square woven nylon mesh stretched between polyvinyl chloride pipe frames to form a 3-m-square and 4.6m-deep pen. Floats were attached to the top of the frame. Each net-pen was anchored in place on a flat bottom and in water shallow enough that the bottom of the net-pen was on the lake or river bottom and the top of the net was at or within $0.5 \mathrm{~m}$ of the surface. Netpens were installed in close proximity to the weigh-in site where they were unlikely to be damaged or dislodged by waves or water currents, yet would have water quality typical of the open water of the lake or river. Water temperature and dissolved oxygen were measured at depths of $0.1 \mathrm{~m}, 2.5 \mathrm{~m}$, and several centimeters above the bottom of each net-pen at 11001300 hours on each day of the postrelease mortality trial for all events. In 2007, water temperature was also measured at 15-min intervals with temperature loggers placed inside a randomly selected net-pen at $0.1 \mathrm{~m}$ below the surface, $2.5 \mathrm{~m}$ below the surface, and $0.1 \mathrm{~m}$ above the bottom.

Eight to 10 reference fish were also stocked into each net-pen in each tournament to detect any lethal effects of net-pen confinement (e.g., oxygen depletion, wave disturbance). The reference fish were adult walleyes captured by electrofishing at locations near the tournament site and transported in aerated hauling tanks. Reference fish collection was conducted by experienced fisheries agency personnel who employed fish handling procedures appropriate for the collection and transport conditions to ensure minimal stress to the fish. Among events, electrofishing power output and water conductivity resulted in power density transfers of $169-547 \mu \mathrm{W} / \mathrm{cm}^{3}$. Assessments of injurious power densities are not available for walleyes, but the power densities used are well below those found to injure channel catfish Ictalurus punctatus and several centrarchid species (Miranda 2005). The reference fish were given a partial pelvic fin clip and stocked into each net-pen 10-20 h before the tournament-caught fish were stocked.

Net-pens were monitored daily to record and remove dead and floating fish but were not raised. After $5 \mathrm{~d}$, the net-pens were raised, numbers of dead and live fish were recorded, and survivors were released. Some of the dead fish in the Green Bay and Menominee events in 2006 , where water temperatures exceeded $25^{\circ} \mathrm{C}$, were severely decomposed. In these events, numbers of dead fish were determined by subtracting the numbers of surviving reference and tournament-caught fish from the numbers stocked. Total lengths were measured for all intact fish in 12 of the 14 tournaments. Postrelease mortality was the percentage of tournament-caught fish that died, and reference fish mortality was the percentage of reference fish that died.

Ambient water temperature variables.-Mortality of tournament-caught walleyes has been consistently shown to increase at higher water temperatures (Hoffman et al. 1996; Graeb et al. 2005; Schramm et al. 2008). To identify a temperature metric that may effectively predict walleye mortality and to better understand how temperature affects the survival of tournament-caught walleyes, we measured a suite of ambient temperature variables that may affect fish at the time of capture and during retention in the net-pens: mean, maximum, and minimum surface water temperature; mean, maximum, and minimum bottom water temperature; change in surface and bottom temperature; and temperature on the day of the tournament (tournament temperature). All ambient temperature measurements were obtained at the net-pens at $0.1 \mathrm{~m}$ (surface), $2.5 \mathrm{~m}$ from the surface, and $3.0-4.5 \mathrm{~m}$ (bottom of the net-pen). In 2006, ambient temperatures were based on water temperatures measured daily at midday (1100-1300 hours); thus, mean, maximum, and change in temperatures were based on 5-6 daily measurements of temperature during the postrelease mortality assessment, and tournament temperature was the water temperature measured at $2.5 \mathrm{~m}$ from the surface on the day of the tournament. The temperature at $2.5 \mathrm{~m}$ was used to minimize the thermal variation resulting from warming of surface waters throughout a day. Ambient temperature metrics for 2007 were based on data from the temperature loggers. Therefore, in 2007, mean, maximum, and change in temperature were based on 15-min measurements of temperature throughout the postrelease mortality assessment, and tournament temperature was the mean surface water temperature on the day of the tournament.

Data analysis.-Associations of mortality measures (initial mortality, prerelease mortality, postrelease mortality, and reference fish mortality) with ambient water temperature variables and tournament variables (median live-well water temperature [hereafter, livewell temperature], median live-well dissolved oxygen concentration [hereafter, live-well oxygen], and median of the maximum reported depth at which fish were caught [hereafter, catch depth]) were evaluated with Spearman rank correlation. Differences between postrelease mortality of tournament-caught fish and reference fish mortality were tested using mixed-model analysis of variance (ANOVA; PROC MIXED; SAS 2006), tournament-caught and reference fish serving as the treatment effect; event, net-pen nested within event, and event-treatment interaction as random effects, and 
TABLE 1.-Location, angler participation, and catch for 14 walleye tournaments assessed to measure the mortality of tournament-caught fish in 2006 and 2007.

\begin{tabular}{|c|c|c|c|c|c|c|}
\hline Site & Water body & Date & $\begin{array}{l}\text { Number } \\
\text { of boats }\end{array}$ & $\begin{array}{c}\text { Number } \\
\text { of fish caught }\end{array}$ & $\begin{array}{c}\text { Weight } \\
\text { of fish caught }(\mathrm{kg})\end{array}$ & $\begin{array}{c}\text { Average fish } \\
\text { weight }(\mathrm{kg})\end{array}$ \\
\hline Arkdale, Wisconsin & Petenwell Lake & 22 Apr 2006 & 72 & 219 & 151.0 & 0.7 \\
\hline Red Wing, Minnesota & Mississippi River & 3 May 2006 & 142 & 506 & 541.8 & 1.1 \\
\hline Devils Lake, North Dakota & Devils Lake & 7 Jun 2006 & 151 & 716 & 976.1 & 1.4 \\
\hline Green Bay, Wisconsin & Lake Michigan & 12 Jul 2006 & 148 & 629 & $1,052.1$ & 1.7 \\
\hline Menominee, Michigan & Lake Michigan & 29 Jul 2006 & 61 & 246 & 497.5 & 2.0 \\
\hline Escanaba, Michigan & Lake Michigan & 6 Sep 2006 & 79 & 213 & 347.3 & 1.6 \\
\hline Pierre, South Dakota & Lake Oahe & 4 Oct 2006 & 44 & 147 & 167.5 & 1.1 \\
\hline Trenton, Michigan & Detroit River & 11 Apr 2007 & 146 & 661 & 756.2 & 1.1 \\
\hline Red Wing, Minnesota & Mississippi River & 2 May 2007 & 148 & 568 & 632.1 & 1.1 \\
\hline Winneconne, Wisconsin & Wolf River & 2 Jun 2007 & 89 & 340 & 297.4 & 0.9 \\
\hline Isle, Minnesota & Mille Lacs & 16 Jun 2007 & 83 & 301 & 213.9 & 0.7 \\
\hline Oconto, Wisconsin & Lake Michigan & 7 Jul 2007 & 81 & 295 & 520.1 & 1.8 \\
\hline Escanaba, Michigan & Lake Michigan & 13 Jul 2007 & 86 & 190 & 371.4 & 1.9 \\
\hline Bemidji, Minnesota & Lake Bemidji & $21 \mathrm{Jul} 2007$ & 77 & 379 & 410.7 & 1.1 \\
\hline
\end{tabular}

arcsine-square-root-transformed mortality rate as the response variable. The total lengths of tournamentcaught and reference fish and of those that survived and died during postrelease mortality assessment were compared with mixed-model ANOVA with treatment (tournament-caught or reference fish), mortality, and treatment-mortality interactions as fixed effects and with event, treatment-event, mortality-event, and treatment-mortality-event interactions as random effects.

Logistic regression (PROC LOGISTIC; SAS 2006) was used to determine environmental and tournament variables that best predicted the probability of mortality of tournament-caught walleyes. Separate models were developed for three levels $(\leq 10 \%, \leq 20 \%$, and $\leq 30 \%)$ of prerelease, postrelease, and reference fish mortality. Candidate models for predicting mortality included, individually and in combination, ambient temperature and tournament metrics that were significantly correlated with and could be expected to influence prerelease, postrelease, or reference fish mortality. Candidate models for reference fish mortality included, in addition to ambient water temperature, only livewell water temperature, as other tournament metrics (e.g., catch depth, live-well oxygen) would not be expected to affect reference fish. Live-well temperature, although measured in anglers' boats, was included as an approximation of water temperature in the holding tanks in electrofishing boats and in transport trucks. Akaike's information criterion for small samples (AIC ) was used to identify the best supported of the candidate models to predict mortality. Models with $\Delta \mathrm{AIC}_{c}\left(\mathrm{AIC}_{c, i}-\mathrm{AIC}_{c, \text { min }}\right.$, where $\mathrm{AIC}_{c, \text { min }}$ is the $\mathrm{AIC}_{c}$ score for the best-supported model [lowest AIC score]) less than 2.0 were considered to have similar support (i.e., to predict mortality similarly to the "best- supported" model [ $\triangle \mathrm{AIC}_{c}=0$ ] as identified by $\mathrm{AIC}_{c}$ scores [Burnham and Anderson 2004]). Initially, we used $\mathrm{AIC}_{c}$ analysis of logistic regression models to identify the best single ambient temperature variable for predicting prerelease, postrelease, and reference fish mortality and then entered only one ambient-temperature variable in the mortality models.

Goodness of fit was evaluated for each model by the value of $\hat{C}$ ( $\hat{C}=$ deviance/df, where deviance is $-2 \cdot \log$ likelihood for the model) and the adjusted value of $R^{2}$ specific for logistic regression (SAS 2006). Values of $\hat{C}$ near 1.0 indicate that the data fit the model; models with $\hat{C}$ greater than 0.7 and less than 2.0 were interpreted as adequate fits (Agresti 2002:155). Adjusted $R^{2}$ ranges from 0 to $1, R^{2}=1$ being the best fit.

\section{Results \\ Tournament Conditions}

Among tournaments, participation ranged from 88 to 302 anglers, or 44-151 boats (Table 1). Saugers comprised approximately $30 \%$ of the fish weighed in at the two Red Wing events and $5 \%$ of the fish weighed in at the Pierre event. No saugers were weighed at the other 11 events. Mean weights of walleyes and saugers weighed in ranged from 0.7 to $2.0 \mathrm{~kg}$ among events.

\section{Tournaments}

Tournament temperature increased from $13-19^{\circ} \mathrm{C}$ for the first three tournaments, peaked at $26-27^{\circ} \mathrm{C}$ for the Green Bay and Menominee events, and then declined to $15^{\circ} \mathrm{C}$ at the last event (Table 2). For all events except Menominee, water temperatures throughout the 5-d postrelease retention period were relatively uniform from the top to the bottom of the net-pens (Table 3), indicating the water body was not thermally stratified or the net-pens were set in epilimnetic water. 
TABLE 2.-Lake or river water temperature on the day of the tournament and maximum catch depth, live-well water temperature, and live-well dissolved oxygen (DO) in 14 walleye tournaments in 2006 and 2007. The 75th-percentile catch depths are those at or above which $75 \%$ of the anglers caught the fish that they weighed in. The 75 th-percentile live-well temperatures are those at or below the temperatures measured in $75 \%$ of the boat live wells. The 75 th-percentile live-well DO concentrations are those at or above the DO concentrations in $75 \%$ of the boat live wells. The values in parentheses are numbers of angler teams interviewed and live wells measured.

\begin{tabular}{|c|c|c|c|c|c|c|c|}
\hline \multirow[b]{2}{*}{ Site } & \multirow[b]{2}{*}{$\begin{array}{c}\text { Tournament } \\
\text { temperature }\left({ }^{\circ} \mathrm{C}\right)\end{array}$} & \multicolumn{3}{|c|}{ Range } & \multicolumn{3}{|c|}{ 75th percentile } \\
\hline & & Depth (m) & $\begin{array}{c}\text { Live-well } \\
\text { temperature }\left({ }^{\circ} \mathrm{C}\right)\end{array}$ & $\begin{array}{c}\text { Live-well DO } \\
(\mathrm{mg} / \mathrm{L})\end{array}$ & $\begin{array}{l}\text { Depth } \\
(\mathrm{m})\end{array}$ & $\begin{array}{c}\text { Live-well } \\
\text { temperature }\left({ }^{\circ} \mathrm{C}\right)\end{array}$ & $\begin{array}{l}\text { Live-well DO } \\
(\mathrm{mg} / \mathrm{L})\end{array}$ \\
\hline \multicolumn{8}{|c|}{2006} \\
\hline Arkdale & $13.0^{\mathrm{a}}$ & $0.9-6.7(31)$ & $11.9-15.5(32)$ & $6.0-13.0(32)$ & 4.0 & 13.7 & 9.3 \\
\hline Red Wing & $14.5^{\mathrm{a}}$ & $1.2-7.6(23)$ & $14.9-17.9$ (24) & $5.5-10.8(24)$ & 4.6 & 15.7 & 8.3 \\
\hline Devils Lake & $18.9^{\mathrm{a}}$ & $0.6-7.9(30)$ & $16.8-21.9(29)$ & $2.6-9.1(29)$ & 2.4 & 20.6 & 6.3 \\
\hline Green Bay & $26.5^{\mathrm{a}}$ & $1.2-9.1(26)$ & $16.5-27.7$ (27) & $2.4-8.5(27)$ & 7.0 & 25.9 & 4.5 \\
\hline Menominee & $26.8^{\mathrm{a}}$ & $2.1-10.4(48)$ & $18.7-25.0(48)$ & $2.2-9.2(48)$ & 7.3 & 22.3 & 5.3 \\
\hline Escanaba & $20.6^{\mathrm{a}}$ & $2.4-18.3(24)$ & $20.1-22.3(24)$ & $4.3-14.3(24)$ & 9.1 & 21.8 & 7.4 \\
\hline Pierre & $15.4^{\mathrm{a}}$ & $3.0-15.2(40)$ & $12.8-17.1(21)$ & $1.5-9.3(21)$ & 9.1 & 15.9 & 5.9 \\
\hline \multicolumn{8}{|c|}{2007} \\
\hline Trenton & $4.1^{\mathrm{b}}$ & $3.4-13.7$ (79) & $3.5-4.9(93)$ & $5.1-15.6(93)$ & 6.7 & 4.1 & 11.9 \\
\hline Red Wing & $16.8^{\mathrm{b}}$ & $1.2-9.1(74)$ & $12.3-18.4(110)$ & $2.5-13.6(110)$ & 6.1 & 17.6 & 7.4 \\
\hline Winneconne & $22.0^{\mathrm{b}}$ & $1.2-6.1(61)$ & $20.7-23.5(43)$ & $2.7-8.5(43)$ & 5.5 & 22.8 & 5.1 \\
\hline Isle & $20.7^{\mathrm{b}}$ & $4.3-9.8(39)$ & $20.0-23.9$ (44) & $2.4-10.3(44)$ & 8.5 & 23.1 & 5.7 \\
\hline Oconto & $18.0^{\mathrm{b}}$ & $2.1-10.7(47)$ & $6.6-26.8(45)$ & $3.0-8.2(43)$ & 7.0 & 25.4 & 5.0 \\
\hline Escanaba & $15.3^{\mathrm{b}}$ & $1.2-22.6(76)$ & $13.6-21.6(66)$ & $4.2-9.6(66)$ & 7.2 & 20.2 & 7.0 \\
\hline Bemidji & $20.5^{\mathrm{b}}$ & $1.8-10.7(26)$ & $19.2-31.0(62)$ & $1.9-10.3(62)$ & 9.8 & 23.3 & 5.2 \\
\hline
\end{tabular}

${ }^{a}$ Measured at $2.5 \mathrm{~m}$ below the surface at the net-pens on the afternoon of the tournament.

${ }^{\mathrm{b}}$ Mean of water temperatures measured at $0.1 \mathrm{~m}$ below the surface throughout the day of the tournament.

At Menominee, the temperature measurements at the bottom of the net-pens were $8-10^{\circ} \mathrm{C}$ cooler than temperatures at middepth and the top of the net-pen during the first $3 \mathrm{~d}$ of the postrelease mortality evaluation; bottom temperatures were similar to middepth and surface temperatures on days 4 and 5 as a result of increased discharge from the Menominee River during and after a rainstorm.

Dissolved oxygen remained above $6 \mathrm{mg} / \mathrm{L}$ at all depths in the net-pens throughout the postrelease mortality trials in all events except Green Bay (Table 3). Here, dissolved oxygen was $0.1-0.3 \mathrm{mg} / \mathrm{L}$ at the bottom of the net-pens on day 4; concurrent measurements were greater than or equal to $6.9 \mathrm{mg} / \mathrm{L}$ at middepth and near the surface among the four net-pens. Duration of the hypoxic condition is not known because dissolved oxygen was only measured once daily.

\section{Tournaments}

Tournament temperature ranged from $4-22^{\circ} \mathrm{C}$ (Table 2). Water temperatures in the net-pens throughout each 5-d postrelease retention period were relatively stable and uniform from the top to the bottom (Table 3) at Trenton, Red Wing, Winneconne, Isle, and Bemidji, indicating the water body was not thermally stratified or the net-pens were set in epilimnetic water. Water temperatures fluctuated widely at the Oconto and
Escanaba events on Lake Michigan, but the temperature fluctuations were similar throughout the water column (i.e., change in surface temperature coincided with similar changes at 2.5 and $4.5 \mathrm{~m}$ ).

Dissolved oxygen data were not available for Oconto. Dissolved oxygen remained above $6 \mathrm{mg} / \mathrm{L}$ at all depths in the net-pens throughout the postrelease mortality trials in all other events (Table 3).

\section{Catch and Live-Well Conditions}

Live-well water temperatures measured at the end of the tournament generally were within $1{ }^{\circ} \mathrm{C}$ of the tournament temperature (Table 2). In the Green Bay and Menominee events in 2006, water temperature in most live wells was below tournament temperature. In 2007 , live-well temperature was $6^{\circ} \mathrm{C}$ above tournament temperature for the Oconto event. Although oxygen concentrations less than $3 \mathrm{mg} / \mathrm{L}$ were recorded in individual live wells in eight tournaments, concentrations were greater than or equal to $4.5 \mathrm{mg} / \mathrm{L}$ in at least $75 \%$ of the live wells at all events.

Fish weighed in were caught at various depths in all events (Table 2). Catch depth was less than $5 \mathrm{~m}$ in five events and 7.9-9.1 $\mathrm{m}$ in three events. In all events, at least $75 \%$ of the anglers caught their fish at depths less than $9.8 \mathrm{~m}$. Three or fewer fish with symptoms of hyperbuoyancy were observed in the release boat tanks at each event. 
TABLE 3.- Ranges of water temperature and dissolved oxygen at the surface $(0.1 \mathrm{~m})$, middepth $(2.5 \mathrm{~m}$ below the surface), and the bottom in net-pens during 5-d postrelease mortality assessments in 14 walleye tournaments in 2006 and 2007.

\begin{tabular}{|c|c|c|c|c|c|c|}
\hline \multirow[b]{2}{*}{ Site } & \multicolumn{3}{|c|}{ Water temperature $\left({ }^{\circ} \mathrm{C}\right)$} & \multicolumn{3}{|c|}{ Dissolved oxygen $(\mathrm{mg} / \mathrm{L})$} \\
\hline & Surface & Middepth & Bottom & Surface & Middepth & Bottom \\
\hline \multicolumn{7}{|c|}{2006} \\
\hline Arkdale & $13.0-15.8$ & $12.7-14.5$ & $12.6-13.5$ & $11.9-14.6$ & $11.9-14.4$ & $11.1-13.2$ \\
\hline Red Wing & $14.2-16.1$ & $13.5-15.1$ & $13.2-14.9$ & $10.3-12.5$ & $9.9-11.5$ & $9.6-10.5$ \\
\hline Devils Lake & $17.1-18.9$ & $16.6-19.0$ & $16.5-19.0$ & $8.3-9.1$ & $8.2-9.8$ & $8.0-8.7$ \\
\hline Green Bay & $26.0-28.2$ & $26.1-28.2$ & $25.8-27.4$ & $7.2-12.7$ & $6.0-13.9$ & $0.1-13.2$ \\
\hline Menominee & $25.5-27.5$ & $25.5-27.4$ & $16.1-26.9$ & $6.5-8.6$ & $6.3-8.1$ & $6.3-9.6$ \\
\hline Escanaba & $19.0-20.6$ & $19.0-20.6$ & $19.0-20.7$ & $9.3-9.5$ & $9.1-9.4$ & $9.3-9.5$ \\
\hline Pierre & $15.4-16.7$ & $15.4-16.2$ & $15.3-16.0$ & $8.5-9.8$ & $8.5-9.9$ & $8.2-9.7$ \\
\hline \multicolumn{7}{|c|}{2007} \\
\hline Trenton $^{\mathrm{a}}$ & $3.8-6.3$ & & $3.8-6.1$ & $11.5-12.8$ & & $11.4-12.7$ \\
\hline Red Wing & $15.1-18.3$ & $15.1-17.3$ & $15.1-17.0$ & $10.6-13.7$ & $10.1-12.9$ & $9.9-12.8$ \\
\hline Winneconne $\mathrm{b}^{\mathrm{b}}$ & $17.7-26.3$ & & $17.5-25.8$ & $6.7-8.7$ & & $6.1-8.3$ \\
\hline Isle & $19.3-23.8$ & $19.3-21.2$ & $18.0-21.7$ & $7.0-9.4$ & $8.7-9.5$ & $8.5-9.5$ \\
\hline Oconto $^{c}$ & $11.2-23.1$ & $10.8-22.3$ & $10.7-21.8$ & & & \\
\hline Escanaba & $9.2-19.6$ & $9.0-18.8$ & $8.1-20.3$ & $9.5-10.5$ & $9.8-10.6$ & $9.8-10.5$ \\
\hline Bemidji & $20.1-27.9$ & $20.2-25.6$ & $20.2-24.9$ & $7.3-10.8$ & $6.9-10.8$ & $6.9-10.8$ \\
\hline
\end{tabular}

\footnotetext{
${ }^{a}$ Net-pens set in 2.5 -m-deep water.

b Net-pens set in 3-m-deep water.

${ }^{\mathrm{c}}$ No dissolved oxygen data available.
}

\section{Mortality}

Initial mortality ranged from $0 \%$ at Arkdale to $28 \%$ at Isle (Table 4). Prerelease mortality ranged from 3\% at Red Wing in 2006 to $48 \%$ at Escanaba in 2006. Mean postrelease mortality of tournament-caught fish ranged from $0 \%$ at Arkdale and Trenton to $100 \%$ at Green Bay and Menominee. Mortality of reference fish confined in net-pens with tournament-caught fish ranged from $0 \%$ at Arkdale, Pierre, and Red Wing (2007) to $97 \%$ at Menominee. Postrelease mortality of tournament-caught fish (mean $=81.3 \%$; $\mathrm{SE}=15.8$ ) was greater than mortality of reference fish (mean = 56.9\%; $\mathrm{SE}=15.8 ; F_{1,13}=5.40 ; P<0.037$ ).
Tournament-caught fish (grand mean $\pm \mathrm{SE}=48.9$ $\pm 0.4 \mathrm{~cm}, n=446$; range of means among tournaments $=42.3-53.4 \mathrm{~cm}$ ) were larger than reference fish (grand mean $\pm \mathrm{SE}=45.8 \pm 0.3 \mathrm{~cm}, n=446$; range of means among tournaments $=40.3-52.0 \mathrm{~cm} ; F_{1,5}=5.56 ; P=$ $0.065)$. The differential mortality between reference and tournament-caught fish was probably not due to size, as mean length of walleyes that died during 5-d retention $(47.8 \mathrm{~cm}$; $\mathrm{SE}=0.39 ; n=403)$ did not differ $\left(F_{1,5}=0.57 ; P=0.485\right)$ from those that survived (47.3 $\mathrm{cm} ; \mathrm{SE}=0.35 ; n=405)$, and the mortality-treatment (i.e., tournament-caught or reference fish) interaction was not significant $\left(F_{1,5}=1.29 ; P=0.308\right)$.

TABLE 4.- - Initial, prerelease, postrelease, and reference fish mortality (\%) for 14 walleye tournaments in 2006 and 2007. The postrelease and reference fish mortality are the mean \pm SE percentages of fish that died after $5 \mathrm{~d}$ in four net-pens.

\begin{tabular}{|c|c|c|c|c|}
\hline \multirow[b]{2}{*}{ Site } & \multirow{2}{*}{$\begin{array}{c}\text { Initial } \\
\text { mortality }\end{array}$} & \multirow{2}{*}{$\begin{array}{c}\text { Prerelease } \\
\text { mortality }\end{array}$} & \multicolumn{2}{|c|}{ Postrelease mortality } \\
\hline & & & Tournament-caught fish & Reference fish \\
\hline Arkdale & 0 & 3.7 & $0 \pm 0$ & $0 \pm 0$ \\
\hline Red Wing & 1.2 & 2.8 & $30.0 \pm 12.9$ & $9.4 \pm 5.6$ \\
\hline Devils Lake & 2.0 & 4.4 & $2.5 \pm 2.5$ & $2.5 \pm 2.5$ \\
\hline Green Bay & 13.2 & 54.2 & $100 \pm 0$ & $47.5 \pm 6.3$ \\
\hline Menominee & 6.9 & 33.7 & $100 \pm 0$ & $90.6 \pm 6.0$ \\
\hline Escanaba & 20.2 & 47.9 & $93.3 \pm 2.7$ & $87.5 \pm 5.1$ \\
\hline Pierre & 0 & 16.3 & $12.5 \pm 4.8$ & $0 \pm 0$ \\
\hline Trenton & 2.7 & 2.9 & $0 \pm 0$ & $0 \pm 0$ \\
\hline Red Wing & 1.4 & 3.9 & $14.5 \pm 6.4$ & $0 \pm 0$ \\
\hline Winneconne & 3.2 & 11.5 & $90.0 \pm 7.1$ & $97.5 \pm 2.5$ \\
\hline Isle & 28.2 & & $82.2 \pm 11.0$ & $22.1 \pm 8.4$ \\
\hline Oconto & 11.5 & 42.7 & $70.0 \pm 4.1$ & $62.5 \pm 11.1$ \\
\hline Escanaba & 8.9 & 45.3 & $70.0 \pm 7.1$ & $92.5 \pm 4.8$ \\
\hline Bemidji & 24.5 & & $75.0 \pm 9.6$ & $2.5 \pm 2.5$ \\
\hline
\end{tabular}


TABLE 5.- Spearman rank correlation coefficients between mortality measures and between those measures and tournament condition variables in 14 walleye tournaments in 2006 and 2007. The values in parentheses are the probabilities that the correlations are different from zero.

\begin{tabular}{|c|c|c|c|c|}
\hline \multirow[b]{2}{*}{ Variable } & \multirow[b]{2}{*}{$\begin{array}{l}\text { Initial mortality } \\
\quad(n=14)\end{array}$} & \multirow[b]{2}{*}{$\begin{array}{l}\text { Prerelease mortality } \\
\qquad(n=12)\end{array}$} & \multicolumn{2}{|c|}{ Postrelease mortality } \\
\hline & & & $\begin{array}{l}\text { Tournament-caught } \\
\quad \text { fish }(n=14)\end{array}$ & $\begin{array}{l}\text { Reference fish } \\
\quad(n=14)\end{array}$ \\
\hline Initial mortality & & & $0.71(<0.01)$ & $0.53(0.05)$ \\
\hline Postrelease mortality & & $0.75(<0.01)$ & & $0.77(<0.01)$ \\
\hline Reference fish mortality & & $0.58(0.05)$ & & \\
\hline Number of boats & $-0.03(0.92)$ & $-0.21(0.51)$ & $-0.14(0.63)$ & \\
\hline Total number of fish weighed in & $0.00(0.99)$ & $-0.37(0.24)$ & $-0.16(0.58)$ & \\
\hline Number of fish per boat & $0.16(0.58)$ & $0.22(0.50)$ & $0.03(0.92)$ & \\
\hline Total weight of fish weighed in & $0.05(0.87)$ & $-0.03(0.93)$ & $0.00(0.99)$ & \\
\hline Weight per boat & $0.33(0.24)$ & $0.45(0.14)$ & $0.34(0.23)$ & \\
\hline Mean surface temperature & & & $0.87(<0.01)$ & $0.58(0.03)$ \\
\hline Maximum surface temperature & & & $0.88(<0.01)$ & $0.63(0.01)$ \\
\hline Minimum surface temperature & & & $0.75(<0.01)$ & $0.29(0.32)$ \\
\hline Tournament temperature & $0.71(<0.01)$ & $0.73(<0.01)$ & $0.89(<0.01)$ & $0.66(0.01)$ \\
\hline Mean bottom temperature & & & $0.85(<0.01)$ & $0.56(0.04)$ \\
\hline Maximum bottom temperature & & & $0.90(<0.01)$ & $0.70(<0.01)$ \\
\hline Minimum bottom temperature & & & $0.66(0.01)$ & $0.23(0.43)$ \\
\hline Change in surface temperature & & & $0.10(0.73)$ & $0.32(0.26)$ \\
\hline Change in bottom temperature & & & $0.20(0.49)$ & $0.55(0.04)$ \\
\hline Median live-well temperature & $0.75(<0.01)$ & $0.75(<0.01)$ & $0.79(<0.01)$ & $0.65(0.01)$ \\
\hline Median live-well oxygen & $-0.53(0.05)$ & $-0.59(0.04)$ & $-0.62(0.02)$ & \\
\hline Median catch depth & $0.64(0.01)$ & $0.72(<0.01)$ & $0.49(0.08)$ & \\
\hline
\end{tabular}

The initial, prerelease, and postrelease mortality rates of tournament-caught walleyes were positively correlated (Table 5). These angler-related mortality measures were not significantly related to number of boats, number of fish weighed in, mean number of fish weighed in per team, total weight of all fish weighed in, or mean weight of fish per boat. Angler-related mortality measures were positively related to most ambient temperature metrics, live-well temperature, and catch depth and negatively related to live-well oxygen. Live-well temperature and live-well oxygen were correlated with tournament temperature (live-well temperature: $r_{s}=0.87, P<0.01, n=14$; live-well oxygen: $\left.r_{s}=-0.83, P<0.01, n=14\right)$. Catch depth, however, was not correlated with tournament temperature $\left(r_{s}=0.42 ; P<0.12 ; n=14\right)$.

Mortality rate of reference walleyes was positively correlated with angler-related mortality measures, but the correlations with initial and prerelease mortality were weak (Table 5). Reference fish mortality was positively related to tournament temperature as well as the temperature variables measured in the net-pens except change in surface temperature.

Mortality was positively related to measures of water temperature, and it was apparent that mortality increased sharply at water temperatures in the range of $15-20^{\circ} \mathrm{C}$ (Figure 1). Of the ambient temperature metrics, $\mathrm{AIC}_{c}$ analysis of ambient temperature variables indicated models with tournament temperature were the best supported models or had support similar to the best supported models (i.e., $\Delta \mathrm{AIC}_{c}<2$ ) for predicting $10 \%$ or less, $20 \%$ or less, or $30 \%$ or less prerelease (Table 6), postrelease (Table 7), and reference fish mortality (Table 8). Thus, tournament temperature was used as the ambient temperature metric for all mortality models.

Based on significant correlations and selection of tournament temperature as the best ambient temperature metric, candidate models for predicting prerelease and postrelease mortality of tournament-caught walleyes included catch depth, live-well oxygen, live-well temperature, and tournament temperature. Most models with three or more predictor variables failed to converge using maximum likelihood estimation due to complete separation of points (i.e., the probability of $\leq 10, \leq 20$, or $\leq 30 \%$ mortality in a tournament was either zero or 100 across the range of the variables). Catch depth was the best variable for predicting the probability that a tournament would have $10 \%$ or less prerelease mortality; $\triangle \mathrm{AIC}_{c}$ was greater than 2 for models with other variables and combinations of variables, but $\Delta \mathrm{AIC}_{c}$ was 2.0145 for tournament temperature (Table 9). Tournament temperature plus catch depth was the best model for predicting that prerelease mortality would not exceed $20 \%$ or $30 \%$, but models with tournament temperature, median live-well temperature, or tournament temperature plus live-well oxygen ( $\leq 20 \%$ prerelease mortality only) also had good support for predicting that prerelease mortality would not exceed $20 \%$ or $30 \%$. Most models had reasonably 

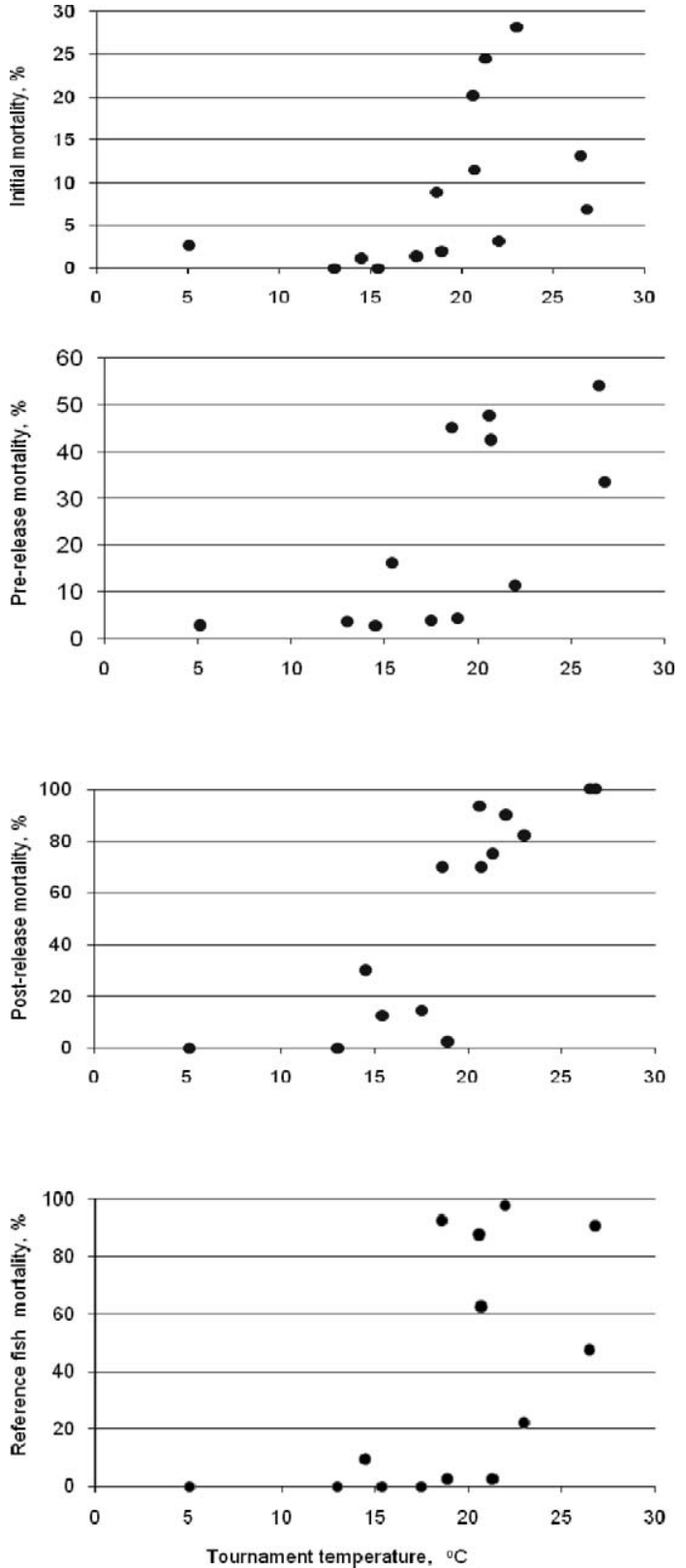

FIGURE 1.-Initial, prerelease, and postrelease mortality of tournament-caught and reference fish at various temperatures. Note that the scales of the vertical axes differ among panels.

good fit to the prerelease mortality data $\left(\hat{C}>0.7 ; R^{2}>\right.$ 0.61 ), but catch depth and tournament temperature + catch depth showed underdispersion $(\hat{C}<0.7)$.

Models with tournament temperature or live-well temperature consistently were the better-supported models for predicting that postrelease mortality would
TABLE 6.-Logistic regression models for predicting that the prerelease mortality of tournament-caught walleyes will not exceed 10, 20, and 30\% according to ambient water temperature variables. Models were developed for the mean, minimum, and maximum bottom temperatures; the mean, minimum, and maximum surface temperatures; and the tournament temperature (see text for definitions). Results are shown only for the four best-supported models ( $\hat{C}=$ deviance/ df; $\mathrm{AIC}_{c}=$ the Akaike information criterion corrected for small sample size).

\begin{tabular}{lcccc}
\hline \multicolumn{1}{c}{ Independent variable } & $\hat{C}$ & $R^{2}$ & $\mathrm{AIC}_{c}$ & ${ }_{c} \mathrm{AIC}_{c}$ \\
\hline \multicolumn{5}{c}{ Mortality $\leq \mathbf{1 0} \%$} \\
Maximum bottom temperature & 0.73 & 0.71 & 12.65 & 0 \\
Maximum surface temperature & 0.79 & 0.68 & 13.21 & 0.56 \\
Tournament temperature & 0.88 & 0.63 & 14.10 & 1.45 \\
Mean surface temperature & 0.89 & 0.62 & 14.25 & 1.60 \\
\multicolumn{5}{c}{ Mortality $\leq \mathbf{2 0} \%$} \\
Tournament temperature & 0.89 & 0.62 & 14.24 & 0 \\
Mean surface temperature & 1.05 & 0.52 & 15.83 & 1.59 \\
Maximum bottom temperature & 1.07 & 0.50 & 16.00 & 1.76 \\
Maximum surface temperature & 1.07 & 0.50 & 16.07 & 1.83 \\
\multicolumn{5}{c}{ Mortality $\leq \mathbf{3 0} \%$} \\
Tournament temperature & 0.89 & 0.62 & 14.24 & 0 \\
Mean surface temperature & 1.05 & 0.52 & 15.83 & 1.59 \\
Maximum bottom temperature & 1.07 & 0.50 & 16.00 & 1.76 \\
Maximum surface temperature & 1.07 & 0.50 & 16.07 & 1.83 \\
\hline
\end{tabular}

not exceed 10, 20, or $30 \%$ (Table 10). Models with catch depth or live-well oxygen had similar support to models with tournament temperature for predicting that a tournament would have $10 \%$ or less postrelease mortality. Models for predicting $10 \%$ or less and $20 \%$ or less postrelease mortality had good fit to the mortality data $\left(\hat{C}=0.72-0.91 ; R^{2}=0.49-0.63\right)$; models using tournament temperature or live-well

TABLE 7.-Logistic regression models for predicting that the postrelease mortality of tournament-caught walleyes will not exceed 10, 20, and $30 \%$ according to ambient water temperature variables. See Table 6 for additional details.

\begin{tabular}{lcccc}
\hline \multicolumn{1}{c}{ Independent variable } & $\hat{C}$ & $R^{2}$ & $\mathrm{AIC}_{c}$ & ${ }_{c} \mathrm{AIC}_{c}$ \\
\hline \multicolumn{5}{c}{ Mortality $\leq \mathbf{1 0} \%$} \\
Maximum surface temperature & 0.68 & 0.57 & 13.27 & 0 \\
Maximum bottom temperature & 0.70 & 0.55 & 13.46 & 0.19 \\
Tournament temperature & 0.72 & 0.53 & 13.72 & 0.45 \\
Mean surface temperature & 0.76 & 0.49 & 14.26 & 0.99 \\
\multicolumn{5}{c}{ Mortality $\leq \mathbf{2 0} \%$} \\
Maximum surface temperature & 0.73 & 0.68 & 13.85 & 0 \\
Maximum bottom temperature & 0.74 & 0.67 & 13.94 & 0.09 \\
Tournament temperature & 0.84 & 0.61 & 15.13 & 1.29 \\
Mean surface temperature & 0.89 & 0.57 & 15.83 & 1.98 \\
\multicolumn{5}{c}{ Mortality $\leq \mathbf{3 0} \%$} \\
Tournament temperature & 0.31 & 0.67 & 8.77 & 0 \\
Mean surface temperature & 0.55 & 0.79 & 11.70 & 2.93 \\
Mean bottom temperature & 0.77 & 0.68 & 14.30 & 5.53 \\
Change in bottom temperature & 0.90 & 0.60 & 15.87 & 7.10 \\
\hline
\end{tabular}


TABLE 8.-Logistic regression models for predicting that the mortality of reference walleyes will not exceed 10,20, and $30 \%$ according to ambient water temperature variables. See Table 6 for additional details.

\begin{tabular}{lcccc}
\hline \multicolumn{1}{c}{ Independent variable } & $\hat{C}$ & $R^{2}$ & $\mathrm{AIC}_{c}$ & ${ }_{c} \mathrm{AIC}_{c}$ \\
\hline \multicolumn{5}{c}{ Mortality $\leq \mathbf{1 0} \%$} \\
Tournament temperature & 0.73 & 0.71 & 13.81 & 0 \\
Maximum bottom temperature & 0.90 & 0.61 & 15.86 & 2.05 \\
Change in bottom temperature & 1.09 & 0.49 & 18.11 & 4.30 \\
Maximum surface temperature & 1.09 & 0.49 & 18.17 & 4.36 \\
Mortality $\leq \mathbf{2 0} \%$ \\
Mournament temperature & 0.73 & 0.71 & 13.81 & 0 \\
Maximum bottom temperature & 0.90 & 0.61 & 15.86 & 2.05 \\
Change in bottom temperature & 1.09 & 0.49 & 18.11 & 4.30 \\
Maximum surface temperature & 1.09 & 0.49 & 18.17 & 4.36 \\
Mortality $\leq \mathbf{3 0} \%$ & & \\
Maximum bottom temperature & 0.97 & 0.56 & 16.68 & 0 \\
Change in bottom temperature & 1.03 & 0.52 & 17.39 & 0.70 \\
Tournament temperature & 1.03 & 0.51 & 17.45 & 0.77 \\
Maximum surface temperature & 1.20 & 0.38 & 19.50 & 2.82 \\
\hline
\end{tabular}

temperature to predict $30 \%$ or less postrelease mortality showed underdispersion $(\hat{C}<0.7)$.

Candidate models for predicting reference fish mortality-only included tournament temperature and median live-well temperature. Models using tournament temperature or live-well temperature had similar support for predicting the probability that reference fish mortality would be $10 \%$ or less, $20 \%$ or less, or $30 \%$ or less in individual tournaments; all models were considered to have good fit to the mortality data (Table 11).

TABLE 9.-Logistic regression models with good support for predicting that the prerelease mortality of tournamentcaught walleyes will not exceed 10,20, and 30\%. Catch depth is the median of the maximum depths at which anglers caught their fish, live-well DO is the median dissolved oxygen concentration measured in anglers' boat live wells, live-well temperature is the median water temperature measured in anglers' boat live wells, and tournament temperature is the surface water temperature on the day of the tournament. See Table 6 for additional details.

\begin{tabular}{|c|c|c|c|c|c|}
\hline \multicolumn{2}{|c|}{ Independent variable } & $\hat{C}$ & $R^{2}$ & $\mathrm{AIC}_{c}$ & $\Delta \mathrm{AIC}_{c}$ \\
\hline \multicolumn{6}{|c|}{ Mortality $\leq 10 \%$} \\
\hline Catch depth & & 0.65 & 0.75 & 11.85 & 0 \\
\hline \multicolumn{6}{|c|}{ Mortality $\leq \mathbf{2 0} \%$} \\
\hline Tournament temperature & + catch depth & 0.55 & 0.82 & 13.65 & 0 \\
\hline Tournament temperature & & 0.91 & 0.62 & 14.24 & 0.58 \\
\hline Live-well temperature & & 0.89 & 0.61 & 14.43 & 0.78 \\
\hline Tournament temperature & + live-well DO & 0.72 & 0.65 & 15.16 & 1.50 \\
\hline \multicolumn{6}{|c|}{ Mortality $\leq \mathbf{3 0} \%$} \\
\hline Tournament temperature & + catch depth & 0.55 & 0.82 & 13.65 & 0 \\
\hline Tournament temperature & & 0.89 & 0.62 & 14.24 & 0.58 \\
\hline Live-well temperature & & 0.91 & 0.61 & 14.43 & 1.52 \\
\hline
\end{tabular}

TABLE 10.-Logistic regression models with good support for predicting that the postrelease mortality of tournamentcaught walleyes will not exceed 10, 20, and 30\%. See Tables 6 and 9 for additional details.

\begin{tabular}{lcccc}
\hline Independent variable & $\hat{C}$ & $R^{2}$ & $\mathrm{AIC}_{c}$ & $\Delta \mathrm{AIC}_{c}$ \\
\hline \multicolumn{5}{c}{ Mortality $\leq \mathbf{1 0} \%$} \\
Tournament temperature & 0.72 & 0.53 & 13.72 & 0 \\
Catch depth & 0.73 & 0.53 & 13.83 & 0.12 \\
Live-well temperature & 0.77 & 0.49 & 14.31 & 0.59 \\
Live-well DO & 0.77 & 0.49 & 14.33 & 0.61 \\
\multicolumn{5}{c}{ Mortality $\leq \mathbf{2 0} \%$} \\
Live-well temperature & 0.91 & 0.63 & 14.77 & 0 \\
Tournament temperature & 0.89 & 0.61 & 15.13 & 0.31 \\
& Mortality $\leq \mathbf{3 0} \%$ & & \\
Tournament temperature & 0.31 & 0.90 & 8.77 & 0 \\
Live-well temperature & 0.37 & 0.87 & 9.55 & 0.78 \\
\hline
\end{tabular}

Although the best-supported model for predicting mortality varied among measures (i.e., reference, prerelease, postrelease) and levels (i.e., $\leq 10, \leq 20$, $\leq 30 \%$ ) of mortality, tournament temperature was consistently identified as the best predictor of mortality. Given the overall support of tournament temperature as a predictor of mortality and the relative ease of measuring it, we modeled the probability of the three mortality levels against tournament temperature for prerelease, postrelease, and reference fish mortality. Among all mortality estimates, the probability of mortality not exceeding 10, 20, or $30 \%$ declined sharply at tournament temperatures between $14^{\circ} \mathrm{C}$ and $18^{\circ} \mathrm{C}$ (Figure 2). The probabilities that mortality would not exceed specified ranges occurred at lower tournament temperatures for postrelease mortality than for prerelease mortality. For example, a 0.8 probability that prerelease mortality would not exceed $20 \%$ occurred at a $17.5^{\circ} \mathrm{C}$ tournament temperature, whereas a 0.8 probability that postrelease mortality would not exceed $20 \%$ occurred at $14.5^{\circ} \mathrm{C}$ tournament temperature.

TABLE 11.-Logistic regression models with good support for predicting that the mortality of reference walleyes will not exceed 10, 20, and 30\%. See Tables 6 and 9 for additional details.

\begin{tabular}{lcccc}
\hline \multicolumn{1}{c}{ Independent variable } & $\hat{C}$ & $R^{2}$ & $\mathrm{AIC}_{c}$ & $\Delta \mathrm{AIC}_{c}$ \\
\hline & Mortality $\leq \mathbf{1 0} \%$ & & \\
Tournament temperature & 0.73 & 0.53 & 13.81 & 0 \\
Live-well temperature & 0.81 & 0.50 & 14.81 & 1.01 \\
& Mortality $\leq \mathbf{2 0} \%$ & & \\
Tournament temperature & 0.73 & 0.53 & 13.81 & 0 \\
Live-well temperature & 0.81 & 0.49 & 14.81 & 1.01 \\
& Mortality $\leq \mathbf{3 0} \%$ & & \\
Live-well temperature & 1.03 & 0.38 & 17.43 & 0 \\
Tournament temperature & 1.03 & 0.38 & 17.45 & 0.03 \\
\hline
\end{tabular}



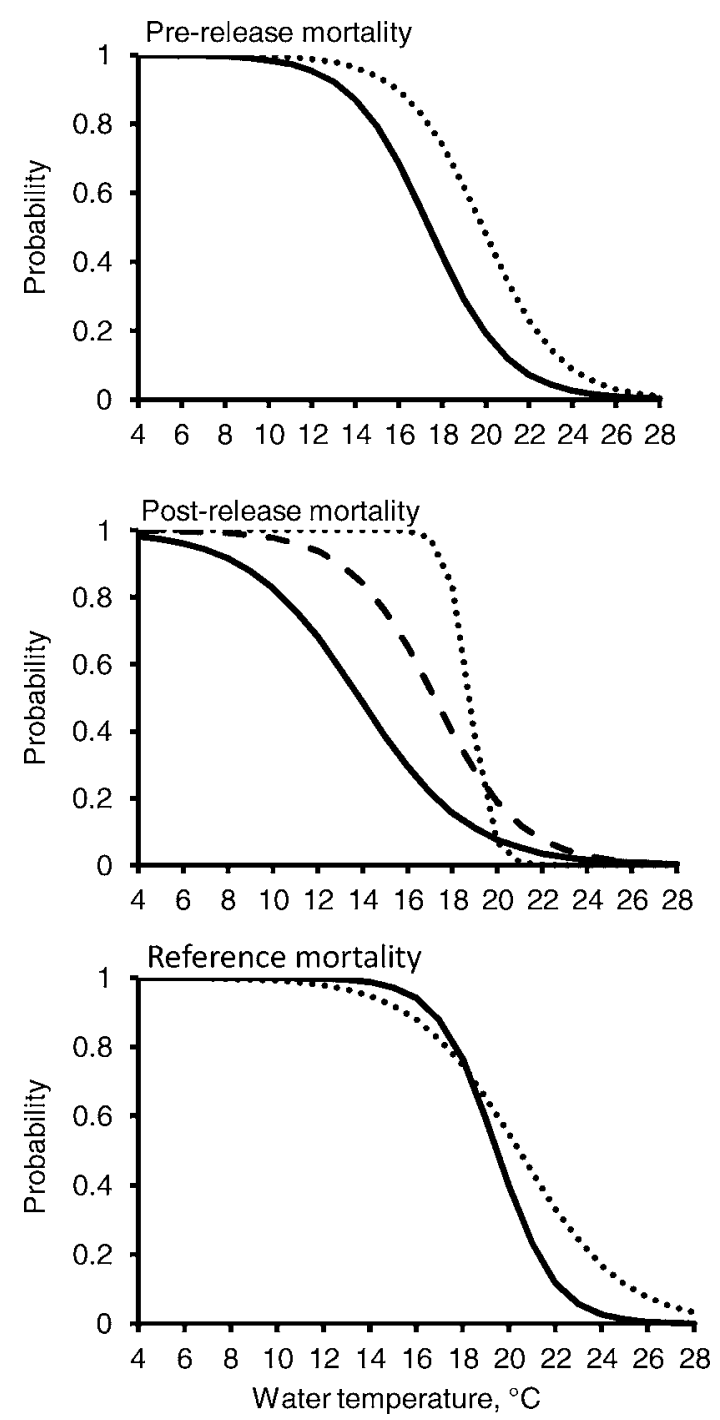

FIGURE 2.-Probability that the prerelease and postrelease mortality of tournament-caught walleyes and the mortality of reference walleyes will not exceed 10\% (solid lines), $20 \%$ (dashed line), or $30 \%$ (dotted lines) as a function of tournament temperature. The dashed and solid lines are almost coincident for prerelease and reference walleye mortality.

Equivalent probabilities that mortality would not exceed specified levels also occurred at lower temperatures for postrelease mortality of tournament-caught fish than for reference fish. For example, a 0.6 probability that postrelease mortality was $10 \%$ or less occurred at a tournament temperature of approximately $13^{\circ} \mathrm{C}$ but at a tournament temperature of approximately $19^{\circ} \mathrm{C}$ for reference fish; similarly, the 0.6 probability of postrelease mortality $20 \%$ or less occurred at $17^{\circ} \mathrm{C}$ for

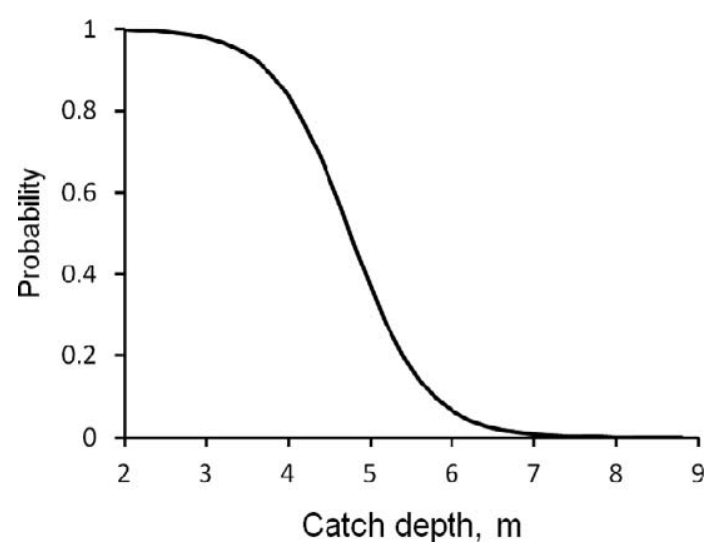

FIGURE 3.-Probability that the prerelease mortality of tournament-caught walleyes will not exceed $10 \%$ as a function of the median catch depth.

tournament-caught fish but at about $19^{\circ} \mathrm{C}$ for reference fish.

Catch depth had good support as a predictor of prerelease mortality. The probability of prerelease mortality exceeding $10 \%$ increased rapidly at $4 \mathrm{~m}$ (Figure 3). Models with catch depth and tournament temperature were the best predictors of prerelease mortality of $20 \%$ or less, or $30 \%$ or less (Table 9). The probability of exceeding set mortality levels occurred at lower temperatures as depth increased (Figure 4).

\section{Discussion}

Assessments of mortality of tournament-caught fish commonly report initial mortality, the proportion of fish judged dead or nonreleasable at weigh-in. This statistic is readily available from tournament records

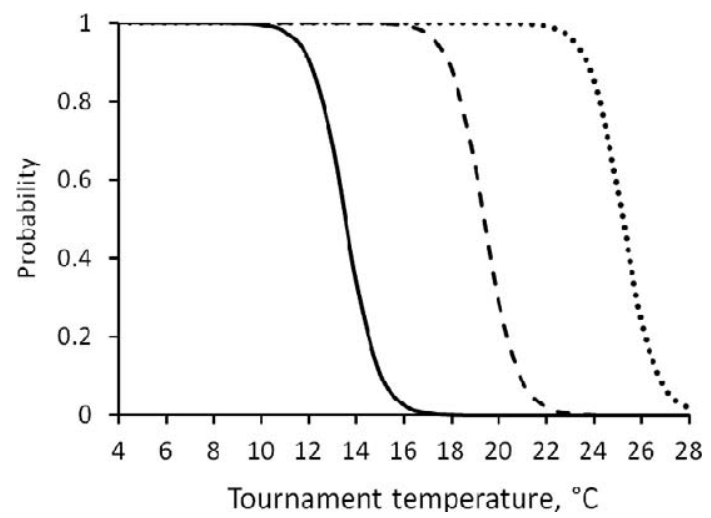

FIGURE 4.- Probability that the prerelease mortality of tournament-caught walleyes will not exceed $20 \%$ as a function of tournament temperature for walleyes caught at depths of 3 (dotted line), 6 (dashed line), and $9 \mathrm{~m}$ (solid line). 
and, thus, facilitates comparisons among tournaments. Our analyses have emphasized prerelease mortality (a measure of all fish that die before release and includes initial mortality) as an estimator of short-term mortality of tournament-caught fish because we consider it a more biologically and managerially informative measure than initial mortality. Prerelease mortality consistently was greater (and, in most cases, substantially greater) than initial mortality. Estimating prerelease mortality allows any fish judged nonreleasable at weigh-in to recover, but we suggest the greater importance of prerelease mortality compared with initial mortality is that it provides a better prediction of fish that are likely to die soon after release. Dead fish at the weigh-in or release site after a tournament is a common complaint about tournaments. Thus, prerelease mortality can be used to evaluate mortality of tournament-caught walleyes and to anticipate dead fish at tournament release sites after a tournament.

Fishery managers, tournament anglers and organizations, and the public are interested in the total mortality of tournament-caught fish. Total mortality is determined from the numbers of fish that die before release and the proportions of fish that die during postrelease mortality assessments. Although easily calculated, we have not reported total mortality and recommend caution in doing so. Initial and prerelease mortality can be measured accurately and clearly linked to tournament activities (e.g., angler capture, live-well conditions, fish handling prior to and during weigh-in), but that is not the case for postrelease mortality.

Some postrelease mortality of tournament-caught fish can be attributed to a delayed effect of an acute stressor, such as a hook wound to an organ, but there is a growing body of evidence that indicates much of postrelease mortality may result from an accumulation of sublethal stressors. Carmichael et al. (1984) demonstrated a cumulative effect of sublethal stressors on juvenile largemouth bass $M$. salmoides in an aquaculture environment in which fish are sequentially stressed by harvest, handling, and being transported. Schramm et al. (1987) recognized that live-release fishing tournaments are analogous to an aquaculture situation in which fish are subjected to multiple, sequential stressors and suggested that a cumulative stress model could explain postrelease mortality of tournament-caught largemouth bass. Subsequent research has demonstrated that the effects of individual, sublethal stressors applied in a relatively brief period of time are cumulative (Barton et al. 1986; Barton and Schreck 1987; Wedemeyer et al. 1990). Walleyes captured in live-release tournaments exhibit changes in physiological parameters associated with elevated activity and cell damage, all of which are indicative of stress (Killen et al. 2003, 2006). Barton and Zitzow (1995) found that concentrations of the stress hormone cortisol in juvenile walleyes increased quickly after handling and declined after 3,6 , and $12 \mathrm{~h}$ in confinement, but then increased after $24 \mathrm{~h}$. Collectively, this information lends further support to the cumulative-stress hypothesis accounting for posttournament mortality.

Although offering an explanation about how tournament conditions can affect survival of walleyes after the tournament, the cumulative-stress hypothesis does little to help identify the portion of postrelease mortality that is attributable specifically to tournament activities (Pollock and Pine 2007). For example, netpen confinement and the additional handling necessary to measure postrelease mortality are additional stressors applied shortly after the other tournament-associated stressors. Conceivably, all fish alive at the time of release may have survived if released into habitats conducive to survival and not subjected to the additional stress associated with postrelease mortality assessment. We suggest that zero or near-zero postrelease mortality estimates indicate low postrelease mortality. Conversely, high postrelease mortality not attributable to experimental conditions (e.g., hypoxia, disturbance of net-pens), particularly when the mortality of tournament-caught fish exceeds the mortality of reference fish, indicates mortality of tournament-caught fish after release is likely. However, in keeping with the cumulative-stress paradigms, the amount of postrelease mortality attributable specifically to tournament capture and handling cannot be accurately quantified. Therefore, estimates of postrelease mortality and total mortality, which include postrelease mortality, should be interpreted cautiously.

We found that prerelease and postrelease mortality increased rapidly within the temperature range of 14$18^{\circ} \mathrm{C}$. These results are in agreement with the onset of high rates of initial mortality of walleyes caught in tournaments in Iowa, Minnesota, Montana, South Dakota, and Wisconsin at approximately $18^{\circ} \mathrm{C}$ (Hoffman et al. 1996) and the increase in postrelease mortality from $18 \%$ at $14^{\circ} \mathrm{C}$ to $79 \%$ at $19^{\circ} \mathrm{C}$ observed by Graeb et al. (2005) at Lake Francis Case, South Dakota. Water temperature clearly affects survival, and average surface temperature when the fish are captured appears to be the best measure for predicting mortality. We find it noteworthy that the temperatures associated with the onset of rapidly increasing mortality are at least $2-4^{\circ} \mathrm{C}$ below the $20-23^{\circ} \mathrm{C}$ optimum (Christie and Regier 1988; Kerr et al. 1997) or preferred temperatures (Coutant 1977) for adult walleyes.

Live-well temperature also had strong support as a predictor of prerelease mortality for mortality rates 
$20 \%$ or less and $30 \%$ or less. Except for $17 \%$ of the anglers who used ice to cool live-well water, contestants filled and flushed their live wells with surface water; thus, live-well temperature is expected to follow tournament temperature and have support as a predictor of mortality. One exception was the Oconto event, in which the live-well temperature exceeded the tournament temperature by $6^{\circ} \mathrm{C}$. The net-pens were located in Lake Michigan, but the weigh-in occurred the Oconto River; the elevated live-well temperatures probably resulted from contestants flushing their live wells with the warmer Oconto River water while they awaited weigh-in.

Catch depth was supported as a predictor of low rates $(\leq 10 \%)$ of prerelease and postrelease mortality but was not, by itself, well supported for predicting the probability of higher mortality rates. This is a consequence of prerelease and postrelease mortality of $10 \%$ or less occurring only in coolwater tournaments. At higher mortality rates that occurred during warmer water temperatures, tournament temperature alone was well supported for predicting prerelease and postrelease mortality, whereas catch depth alone was not well supported. Thus, catch depth appears to affect survival, but the effect of catch depth in the tournaments studied was secondary to, or masked by, water temperature during warmwater tournaments. Further, although catch depth is often assumed to increase as the water warms and walleyes seek their preferred temperature, catch depth was not correlated with tournament temperature. The lack of significant correlation is probably attributable to the locations of the tournaments. As was evident from temperature data collected at the net-pens while monitoring postrelease mortality, thermal profiles, particularly on large lakes such as Lake Michigan, can be complex and dynamic. Consequently, anglers fishing Lake Michigan tournaments in the summer did not necessarily need to fish in deep water to fish in cool water where walleyes were likely to be located.

How depth of capture affected survival is not evident. We observed few hyperbuoyant fish. Barotrauma, or the effect of rapid depressurization that occurs when physoclistous fish such as walleyes are caught from deep water, can have various lethal effects in addition to hyperbuoyancy, including embolism, hemorrhage, and peritoneal rupture (Feathers and Knable 1983). Possibly some hyperbuoyant fish may have been treated by the anglers to relieve overinflated swim bladders ("fizzing") prior to weigh-in because hyperbuoyant fish would have been judged as nonreleasable (unable to maintain a normal position in the water). Although not hyperbuoyant, these fish may have been affected by the other lethal, but less evident, effects of rapid depressurization.

The logistic regression models for predicting reference fish mortality may offer insights into how water temperature affects survival of tournamentcaught walleyes. Of the ambient temperature metrics, water temperature at the bottom of the net-pens (maximum bottom temperature) and tournament temperature consistently had good support for predicting reference fish mortality. Live-well temperature, a tournament metric, was also well supported as a predictor of reference fish mortality. An accurate thermal history for the reference fish prior to stocking into the net-pens is not known because the water temperatures at the capture locations and in holding and transport tanks were not recorded. The reference fish were captured by electrofishing in shallow water and held in boat tanks or truck-mounted transport tanks that, similar to the live wells in tournament boats, were filled with near-surface ambient water. Therefore, tournament temperature and live-well temperature, both of which were among the better-supported models for predicting levels of reference fish mortality, are reasonable approximations of the thermal conditions at and shortly after capture by electrofishing and before stocking into the net-pens. This suggests that relatively brief exposure to elevated temperature immediately after capture and when fish are confined in a live well or hauling tank may affect mortality.

The support for maximum bottom temperature as a predictor of reference fish mortality could indicate that a thermal stressor during the $5 \mathrm{~d}$ of net-pen confinement affected survival. Walleyes are demersal fish, and direct and underwater camera observations during postrelease mortality assessments confirmed that the walleyes stayed on or near the bottom of the net-pens. Thus, water temperature measured at the bottom of the net-pens would be expected to have the most influence on walleye survival after they were stocked into the net-pens. Maximum bottom temperatures were, except for the Green Bay event, at or below the $20-23^{\circ} \mathrm{C}$ preferred temperature range of walleyes (Coutant 1977) for at least part of the 5-d retention period. At six events (Menominee, Escanaba in 2006, Winneconne, Isle, Oconto, and Bemidji), bottom water temperature exceeded $21^{\circ} \mathrm{C}$ for a portion of the 5 -d period when fish were in the net-pens. Thus, relatively brief exposure to elevated temperature of walleyes confined to net-pens may contribute to mortality. Maximum bottom temperatures greater than $21^{\circ} \mathrm{C}$, except for the Green Bay event, were a result of abrupt $4-12^{\circ} \mathrm{C}$ changes in bottom water temperature. Although such abrupt increases in temperature might be expected to affect survival, especially since the 
temperature change increased the bottom temperature to $24^{\circ} \mathrm{C}$ or higher in three of these events, the ambient temperature variable "change in bottom temperature" had less support as a predictor of mortality of reference fish. Thus, it appears that maximum bottom temperature, but not change in bottom temperature, may have contributed to the mortality of walleyes confined to net-pens.

The occurrence of equivalent probabilities of mortality (e.g., 0.6 probability of mortality $\leq 20 \%$ ) of fish retained in net-pens at lower temperatures for tournament-caught than reference walleyes suggests an interaction of water temperature and stress may affect the survival of tournament-caught fish. The tournament-caught and reference fish were held under identical conditions in each tournament. The reference walleyes probably incurred some stress from capture and handling. Nevertheless, stress, and possibly injury, resulting from angler capture, live-well confinement, and handling associated with tournament weigh-in procedures resulted in higher mortality than for fish not subjected to angler capture and weigh-in procedures. Further, it appears that the lethal effect of the additional stress was manifested at lower temperatures or that the threshold for the lethal effect of temperature was lowered by stressors related to angler capture and tournament-related procedures.

Live-well oxygen was significantly related to mortality but was not well supported as a predictor of mortality. Although isolated cases of low live-well oxygen were encountered in these events, $75 \%$ or more of the live wells measured in all 14 events had dissolved oxygen concentrations greater than the 4.0 $\mathrm{mg} / \mathrm{L}$ considered sufficient for nonsalmonid fishes (Davis 1975). In general, the anglers provided suitable dissolved oxygen conditions in the live wells despite the high temperatures and large catches that are conducive to low live-well oxygen concentrations. At the tournament level of analysis employed in this study, we do not consider live-well oxygen concentrations observed in these tournaments to contribute significantly to mortality.

Additional research is needed to determine the effect of water temperature on adult walleyes. A substantial body of research has been developed on the physiological effects of sublethal stressors on tournamentcaught black bass (e.g., Siepker et al. 2007 and references therein). Similar research is needed for walleyes. Physiological stress measures are more efficiently, precisely, and economically measured than mortality (Cooke and Schramm 2007; Pollock and Pine 2007) and may be useful for better understanding the effect of water temperature. However, population effects of tournaments are determined by fish mortality, so studies are also needed that establish relationships between stress and mortality. The results of the present research suggest assessments of mortality and physiological stress should focus on water temperatures in the range of $13-22^{\circ} \mathrm{C}$.

\section{Management Implications}

Water temperature has been shown in this and other studies (Hoffman et al. 1996; Graeb et al. 2005) to have a substantial effect on walleye survival. The results of this research provide a tool that resource managers, tournament organizers, and anglers can use to predict the probability of achieving different survival rates of tournament-caught walleyes from water temperature. Although evidence in this study suggests some mortality of tournament-caught fish occurs after release from tournaments when water temperatures exceed $14^{\circ} \mathrm{C}$, this component of mortality cannot be accurately quantified. On the other hand, prerelease mortality can be accurately measured and is strongly correlated with postrelease mortality. We suggest that decisions related to management of tournaments and evaluations of tournament procedures should be based on prerelease mortality and, further, that mean surface water temperature at the time of the tournament (tournament temperature) is a suitable and easily measured temperature metric for predicting prerelease mortality.

The results of this assessment also suggest there are opportunities for improving the survival of tournamentcaught walleyes. Live-well water temperature may warrant concern for two reasons. First, given water temperature preference of $20-23^{\circ} \mathrm{C}$ (Coutant 1977), most walleyes caught during summer tournaments probably will be caught from water cooler than surface water but retained for up to $8-9 \mathrm{~h}$ in live wells in which the temperatures approximate surface water temperatures. As is evident from temperature measurements obtained while monitoring net-pens, the temperature differential between the surface and $4.5 \mathrm{~m}$ can be as great at $10^{\circ} \mathrm{C}$. Lowering live-well temperature may minimize thermal shock and prevent exposing walleyes to temperatures near or above $18^{\circ} \mathrm{C}$ (or possibly lower for fish subjected to capture and handling), a temperature associated with relatively high probabilities that mortality will exceed $20 \%$ or $30 \%$. Second, if brief exposures to elevated temperatures after capture significantly affect walleye survival, as suggested by the effect of tournament and live-well temperatures on survival of reference fish, putting the fish in cool water immediately after capture and handling may reduce mortality. Manipulating live-well temperature is feasible as demonstrated by several anglers in each of the warmwater tournaments. Because fish are also stressed when handled during weigh-in, this same reasoning 
applies to temperature control throughout weigh-in, in live-release boat tanks, and in selecting sites for releasing fish (viz., the fish should have ready access to cool water). Controlled laboratory experiments are needed to evaluate the independent effect of live-well water temperatures on walleye survival and determine the best temperatures to maximize survival.

\section{Acknowledgments}

This project benefited from the contributions of numerous individuals. Funding for the study was provided by FLW Outdoors; the Iowa Department of Natural Resources; Michigan Department of Natural Resources; MDNR; South Dakota Department of Game, Fish, and Parks; Wisconsin Department of Natural Resources; the U.S. Geological Survey (USGS) Minnesota Cooperative Fish and Wildlife Research Unit; and the USGS Mississippi Cooperative Fish and Wildlife Research Unit. Personnel from the above agencies provided logistical support, collected walleye for the postrelease mortality assessments, and assisted with angler interviews and measurements of temperature and dissolved oxygen in live wells. FLW Outdoors personnel provided valued assistance at all events. Brian Blackwell, Jack Wingate, and three anonymous reviewers provided useful reviews of earlier versions of this manuscript.

\section{References}

Agresti, A. 2002. Categorical data analysis, 2nd edition. Wiley, Hoboken, New Jersey.

Barton, B. A., and C. B. Schreck. 1987. Metabolic cost of acute physical stress in juvenile steelhead. Transactions of the American Fisheries Society 116:257-263.

Barton, B. A., C. B. Schreck, and L. A. Sigismondi. 1986. Multiple acute disturbances evoke cumulative physiological stress responses in juvenile Chinook salmon. Transactions of the American Fisheries Society 115:245251.

Barton, B. A., and R. E. Zitzow. 1995. Physiological responses of juvenile walleyes to handling stress with recovery in saline water. Progressive Fish-Culturist 57:267-276.

Burnham, K. P., and D. R. Anderson. 2004. Multimodel inference: understanding AIC and BIC in model selection. Sociological Methods and Research 33:261304.

Carmichael, G. J., J. R. Tomasso, B. A. Simco, and K. B. Davis. 1984. Confinement and water quality-induced stress associated with hauling largemouth bass. Transactions of the American Fisheries Society 113:767-777.

Christie, G. C., and H. A. Regier. 1988. Measures of optimal thermal habitat and their relationship to yields for four commercial fish species. Canadian Journal of Fisheries and Aquatic Sciences 45:301-314.

Cooke, S. J., and H. L. Schramm Jr. 2007. Catch-and-release science and its application to conservation and manage- ment of recreational fisheries. Fisheries Management and Ecology 14:73-79.

Coutant, C. C. 1977. Compilation of temperature preference data. Journal of the Fisheries Research Board of Canada 34:739-745.

Davis, J. C. 1975. Minimal dissolved oxygen requirements of aquatic life with emphasis on Canadian species: a review. Journal of the Fisheries Research Board of Canada 32:2295-2332.

Edwards, G. P. Jr., R. M. Neumann, R. P. Jacobs, and E. B. O'Donnell. 2004. Impacts of small club tournaments on black bass populations in Connecticut and the effects of regulation exemptions. North American Journal of Fisheries Management 24:811-821.

Feathers, M. G., and A. E. Knable. 1983. Effects of depressurization upon largemouth bass. North American Journal of Fisheries Management 3:86-90.

Fielder, D. G., and B. A. Johnson. 1994. Walleye mortality during live-release tournaments on Lake Oahe, South Dakota. North American Journal of Fisheries Management 14:177-184.

Gilliland, G., and H. Schramm. 2002. Keeping bass alive. BASS/ESPN, Montgomery, Alabama.

Goeman, T. J. 1991. Walleye mortality during a live-release tournament on Mille Lacs, Minnesota. North American Journal of Fisheries Management 11:57-61.

Graeb, B. D. S., J. L. Shepherd, and D. W. Willis. 2005. Delayed mortality of tournament-caught walleyes. North American Journal of Fisheries Management 25:251-255.

Hoffman, G. C., D. W. Coble, R. V. Frie, F. A. Copes, R. M. Bruch, and K. K. Kamke. 1996. Walleye and sauger mortality associated with live-release tournaments on the Lake Winnebago system, Wisconsin. North American Journal of Fisheries Management 16:364-370.

Kerr, S. J., B. W. Corbett, N. J. Hutchinson, D. Kinsman, J. H. Leach, D. Puddister, L. Stanfield, and N. Ward. 1997. Walleye habitat: a synthesis of current knowledge, with guidelines for conservation. Ministry of Natural Resources, Ottawa.

Killen, S. S., C. D. Suski, S. J. Cooke, D. P. Philipp, and B. L. Tufts. 2006. Factors contributing to the physiological disturbance in walleyes during simulated live-release angling tournaments. Transactions of the American Fisheries Society 135:557-569.

Killen, S. S., C. D. Suski, M. B. Morrissey, P. Dyment, M. Furimsky, and B. L. Tufts. 2003. Physiological responses of walleyes to live-release angling tournaments. North American Journal of Fisheries Management 23:1238-1246.

Miranda, L. E. 2005. Refining boat electrofishing equipment to improve consistency and reduce harm to fish. North American Journal of Fisheries Management 25:609-618.

Pollock, K. H., and W. E. Pine III. 2007. The design and analysis of field studies to estimate catch-and-release mortality. Fisheries Management and Ecology 14:123130.

SAS. 2006. Base SAS 9.1.3 procedures guide, 2nd edition. SAS Institute, Cary, North Carolina.

Schramm, H. L. Jr., M. L. Armstrong, A. J. Fedler, N. A. Funicelli, D. M. Green, D. P. Lee, R. E. Manns Jr., B. E. Taubert, and S. J. Waters. 1991. The status of 
competitive sport fishing in North America. Fisheries 16(3):4-12.

Schramm, H. L., W. E. French, and B. Vondracek. 2008. Mortality of walleye caught in live-release tournaments. Pages 625-636 in M. S. Allen, S. Sammons, and M. J. Maceina, editors. Balancing fisheries management and water uses for impounded river systems. American Fisheries Society, Symposium 62, Bethesda, Maryland.

Schramm, H. L. Jr., P. J. Haydt, and K. M. Portier. 1987. Evaluation of prerelease, postrelease and total mortality of tournament-caught largemouth bass in two Florida lakes. North American Journal of Fisheries Management 7:394-402.

Schramm, H. L. Jr., and K. M. Hunt. 2007. Issues, benefits, and problems associated with fishing tournaments in inland waters of the United States: a survey of fishery agency administrators. Fisheries 32:234-243.

Schramm, H. L. Jr., A. R. Walters, J. M. Grizzle, B. H. Beck, L. A. Hanson, and S. B. Rees. 2006. Effects of live-well conditions on mortality and largemouth bass virus prevalence in largemouth bass caught during summer tournaments. North American Journal of Fisheries Management 26:812-825.

Siepker, M. J., K. G. Ostrand, S. J. Cooke, D. H. Wahl, and D. P. Philipp. 2007. A review of black bass, Micropterus spp., catch-and-release angling effects: implications for conservation and management. Fisheries Management and Ecology 14:91-101.

Tufts, B. L., and P. Morlock. 2004. The Shimano water weigh-in system: a "fish-friendly" guide. Shimano Canada Ltd., Whitney, Ontario.

Wedemeyer, G. A., B. A. Barton, and D. J. McLeay. 1990. Stress and acclimation. Pages 451-489 in C. B. Schreck and P. B. Moyle, editors. Methods for fish biology. American Fisheries Society, Bethesda, Maryland.

Wilde, G. R. 1998. Tournament-associated mortality in black bass. Fisheries 23(10):12-22. 